Work and rehabilitation

\section{PARE0016 IMPACT OF AXIAL SPONDYLOARTHRITIS ON PATIENTS' PROFESSIONAL LIFE: RESULTS FROM THE ONLINE SURVEY EMAS OF 638 FRENCH PATIENTS}

Laurent Grange ${ }^{1,2}$, Pascal Claudepierre ${ }^{3}$, René-Marc Flipo ${ }^{4,5},{ }^{6,7}$ Marco GarridoCumbrera $^{8}$, Emilie Desfleurs ${ }^{9}$, Francoise Alliot Launois ${ }^{10}$, Laure Gossec ${ }^{11,12}$

${ }^{1}$ Grenoble Alpes University Hospital, Rheumatology, Echirolles, France;

${ }^{2}$ Association Française de Lutte Antirhumatismale A.F.L.A.R, President, Paris, France; ${ }^{3}$ Henri Mondor University Hospital, Rheumatology, Créteil, France; ${ }^{4}$ Lille University, Lille, France; ${ }^{5}$ Roger Salengro Hospital, Rheumatology, Lille, France; ${ }^{6}$ Universidad de Sevilla, Sevilla, Spain; ${ }^{7}$ Health and Territory Research (HTR), Sevilla, Spain; ${ }^{8}$ Spanish Federation of Spondyloarthritis Associations (CEADE), Madrid, Spain; ${ }^{9}$ Novartis Pharma, Medical affairs, Rueil Malmaison, France; ${ }^{10}$ Association Française de Lutte Antirhumatismale A.F.L.A.R, Vice president, Paris, France; ${ }^{11}$ Sorbonne University, Paris, France $;{ }^{12}$ La Ptitié-Salpêtrière University Hospital, Rheumatology, Paris, France

Background: Axial spondyloarthritis (axSpA) can result in functional limitation and work disability. However, there are little data in the era of biologics.

Objectives: The aim of this analysis was to evaluate the impact of axSpA on professional life.

Methods: Between December 2017 and February 2018, patients followed for axSpA by their rheumatologists or affiliated to the French patients association AFLAR, and self-reporting axSpA, participated in the European Map of Axial Spondyloarthritis (EMAS) cross-sectional patient survey1. Socio-demographics (age, gender, relationship status, educational level, job status), disease activity (BASDAl) and the impact of axSpA on professional life (job choice, working hours, sick leave, unemployment and relationship with colleagues) were collected. The participants who were employed and working at the time of the survey were regrouped as "employed" and the ones employed or on temporary sick leave or students at the time of the survey as "active". No imputation of missing data was performed and the analyses were descriptive.

Results: In France, 638 persons (mean age $41.5 \pm 11.1$ years, 77\% females, mean disease duration $6.9 \pm 8.2$ years, mean BASDAI $5.9 \pm 1.7$ ) participated to the survey. About half of them (51\%) had a university degree. At the time of the survey, $54 \%$ were employed, $26 \%$ in temporary or permanent sick leave, $7 \%$ unemployed, $6 \%$ retired, $5 \%$ homemaker and $2 \%$ students. Overall, $176(28 \%)$ received social compensation for handicap or disability due to their axSpA. Regarding the employed ones ( $n=331), 50 \%$ were unskilled workers, $15 \%$ had an intermediate profession and $23 \%$ a white-collar job. The majority $(73 \%)$ reported working issues related to axSpA in the last 12 months, such as sick leave (60\%), reducing or difficulties to fulfill working hours $(62 \%)$ or missing working hours for health appointments (33\%). Among patients on temporary sick leave $(n=72), 92 \%$ reported that it was the consequence of their axSpA and the mean duration of their temporary sick leave in the last 12 months was $5.4 \pm 4.0$ months. Considering active people $(n=418), 39 \%$ declared that their relationships with their work colleagues were worse since their axSpA. AxSpA had also influenced $55 \%$ of them in their job choice and drove $44 \%$ to adapt their workplace and $34 \%$ to move to another job. Finally, $62 \%$ expressed their fear to lose their job because of axSpA.

Conclusion: In this survey of 638 young axSpA patients, $66 \%$ of participants were active; the impact of the disease on professional life was described as important and often had consequences including permanent sick leave or unemployment. These aspects of axSpA should be better assessed.

\section{REFERENCE}

[1] Gossec L, et al. Diagnostic Delay and Associated Factors in Axial Spondyloarthritis across Europe. Results from the European Map of Axial Spondyloarthritis Survey. Arthritis Rheumatol. 2018 Sep;70 Suppl 9:688

\section{Acknowledgement: Survey supported by Novartis}

Disclosure of Interests: LAURENT GRANGE Consultant for: Laurent Grange has received honoraria from Amgen, Lilly and UCB and research support from Lilly, Amgen, UCB, Expanscience, Mylan, Roche diagnostics and TEVA, Pascal Claudepierre Consultant for: Honoraria from Novartis as steering committe of this survey, René-Marc Flipo Consultant for: Honoraria from Novartis as steering committe of this survey, Marco GarridoCumbrera Consultant for: Honoraria from Novartis as steering committe of this survey, Emilie Desfleurs Employee of: Employee of Novartis Pharma, Francoise Alliot Launois: None declared, Laure Gossec Grant/research support from: AbbVie, BMS, Celgene, Janssen, Lilly, MSD, Novartis-Sandoz, Pfizer, Sanofi, and UCB, Consultant for: AbbVie, Biogen, BMS,
Celgene, Janssen, Lilly, MSD, Nordic Pharma, Novartis-Sandoz, Pfizer, Roche, Sanofi, and UCB, Consultant for: L Gossec has received honoraria from Celgene as investigator for this study DOI: 10.1136/annrheumdis-2019-eular.3742

\section{Arthritis research}

\section{PARE0017 EXPLORING DIFFERENCES IN THE AGE ON ONSET OF JIA BETWEEN MALES AND FEMALES: A PARENT-LED SURVEY}

Richard Beesley ${ }^{1}$, Simon Stones ${ }^{2} .{ }^{1}$ Juvenile Arthritis Research, Tonbridge, United Kingdom; ${ }^{2}$ University of Leeds, School of Healthcare, Leeds, United Kingdom

Background: The etiology of Juvenile Idiopathic Arthritis (JIA) remains unknown, despite a range of proposed mechanisms under investigation [1]. However, previous research has revealed biological differences depending on the age of onset of JIA, independent of the classification based on the number of joints involved [2].

Objectives: In this parent-led study, the age of onset of JIA by both disease subtype and sex of the child were explored, to identify whether there is a difference in age of onset of JIA between males and females. Methods: An online survey was shared via social media, targeted at parents of children and young people (CYP) with JIA. Questions probed the age of symptom-onset and diagnosis (by single year of age), JIA subtype and Rheumatoid Factor (RF) status.

Results: Of the 409 CYP included, 296 had polyarticular (poly) or oligoarticular (oligo) JIA, including extended-oligo JIA (72\% of all respondents). There were no differences between onset among these subtypes; therefore, they were grouped for further analysis, given comparable disease progression and genetic markers among these subtypes. There was no significant difference regarding age of symptom onset between RF-positive and RF-negative CYP. Amongst those with poly/oligo JIA, there was a clear peak of symptom-onset in the first few years of life, with over half experiencing symptoms before their third birthday, and $73 \%$ before the age of five years. Interestingly, the distribution of symptom-onset was significantly different in the poly/oligo JIA group between males and females $(P=0.0093)$, with the onset of poly/oligo JIA appearing to occur earlier in females (Figure 1). Given that some CYP with older-onset JIA are sometimes reclassified as having enthesitis-related arthritis (ERA) when examined in adolescent services, the Mann-Whitney $U$ Test was repeated with only those CYP with JIA onset before the age of seven years. In this case, there remained a significant difference in age of onset of poly/oligo JIA between males and females $(P=0.0061)$.

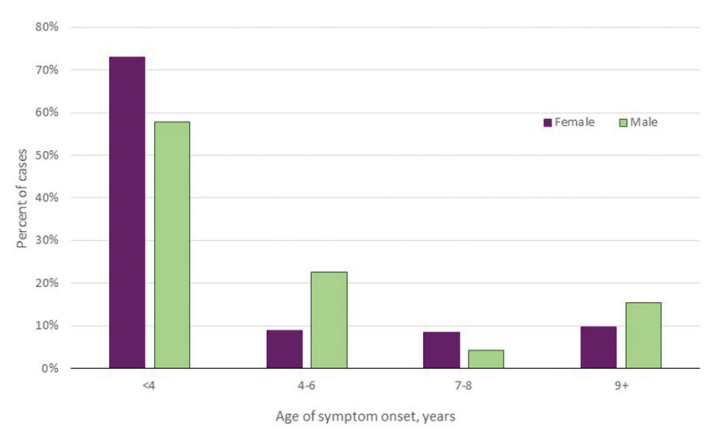

Figure 1. Grouped age of onset of polyarticular and oligoarticular JIA for females and males.

Conclusion: The age of symptom-onset among CYP with poly/oligo JIA differs between males and females, with females tending to exhibit symptoms earlier. This appears not to be attributable to misclassification of JIA subtype, and so this knowledge may assist future diagnoses of JIA. Further research is required to identify which temporal-associated factors may be critical in JIA onset and development.

\section{REFERENCES}

[1] Rigante, et al. The Etiology of Juvenile Idiopathic Arthritis. Clinic Rev Allerg Immunol 2015; 49:253.

[2] Barnes, et al. Biologic similarities based on age at onset in oligoarticular and polyarticular subtypes of juvenile idiopathic arthritis. Arth Rheum 2010; 62:3249-58. 